\title{
Smoking and its Correlation with Inflammatory Markers and Cardiovascular Risks in Pre-Diabetic and Diabetic Patients
}

\author{
Shailaza Shrestha' ${ }^{1}$ Preeti Sharmaㄹ, Pradeep Kumar³, Mahendra Prasad ${ }^{4}$ \\ ${ }^{1}$ Assistant Professor, Department of Biochemistry, Heritage Institute of Medical Sciences, Varanasi, Uttar Pradesh, \\ India. ${ }^{2}$ Associate Professor, Department of Biochemistry, Santosh Medical College and Hospital, Ghaziabad, \\ Uttar Pradesh, India. ${ }^{3}$ Professor, Department of Biochemistry, Santosh Medical College and Hospital, Ghaziabad, \\ Uttar Pradesh, India. ${ }^{4}$ Professor, Department of Biochemistry, Heritage Institute of Medical Sciences, Varanasi, \\ Uttar Pradesh, India.
}

\section{ABSTRACT}

\section{BACKGROUND}

Cigarette consumption increases both the risk of diabetes and diabetic vascular complications. It is associated with dyslipidemia, insulin resistance and inflammation. However, the exact mechanisms are still to be elucidated. In this study, we aimed to compare the levels of inflammatory markers and assess the cardiovascular risks in terms of $\mathrm{CRR}, \mathrm{AI}, \mathrm{AC}$ and AIP among the patients with prediabetes and diabetes.

\section{METHODS}

This study included 100 control subjects, 145 pre-diabetic and 126 diabetic patients. The patients were further categorised into non-smoker (44 pre-diabetes and 40 diabetes) and smoker (101 pre-diabetes and 86 diabetes) groups. Inflammatory biomarkers like fibrinogen, CRP, IL-6, adiponectin and uric acid were assayed with standard kit methods.

\section{RESULTS}

We observed high levels of fibrinogen, CRP, IL-6 and uric acid, and low levels of adiponectin in pre-diabetic and diabetic smoker group compared to their nonsmoker counterparts but the level of statistical significance was achieved in case of adiponectin only. Pre-diabetic smokers also demonstrated significantly high fibrinogen compared to pre-diabetic non-smokers. We also found high cardiovascular risk in pre-diabetic and diabetic individuals irrespective of smoking status. Further we documented significant association of inflammatory markers with cardiac risk indices especially in case of diabetic patients and the association was more profound in the patients who smoked.

\section{CONCLUSIONS}

Thus, from this study, it is evident that both pre-diabetic and diabetic individuals are highly susceptible to CVD risks induced by smoking. Diabetic individuals are further at a great risk compared to pre-diabetic individuals. So, quitting smoking can reverse the unwanted health outcomes of diabetes.

\section{KEY WORDS}

Pre-Diabetes, Diabetes, Smoking, Inflammation, Cardiac Risk Indices

\author{
Corresponding Author: \\ Dr. Preeti Sharma, \\ Department of Biochemistry, \\ Santosh Medical College and Hospital, \\ Ghaziabad, Uttar Pradesh, India. \\ E-mail: prcdri2003@yahoo.co.in
}

DOI: $10.14260 / \mathrm{jemds} / 2019 / 573$

Financial or Other Competing Interests: None.

How to Cite This Article:

Shrestha S, Sharma P, Kumar P, et al. Smoking and its correlation with inflammatory makers and cardiovascular risks in pre-diabetic and diabetic patients. J. Evolution Med. Dent. Sci. 2019;8(33):26332638, DOI: 10.14260/jemds/2019/573

Submission 21-06-2019,

Peer Review 02-08-2019,

Acceptance 08-08-2019,

Published 19-08-2019. 


\section{BACKGROUND}

Smoking not only is the well-known risk factor of diabetes, but is also an important agent which can lead to deterioration of diabetic status leading to end organ damage via increased production of free radicals and inflammatory molecules. A number of studies have documented smoking induced altered metabolism of glucose and lipid in diabetic patients. Smoking increases insulin resistance that culminates in hyperglycaemia and dyslipidemia. These studies also implicated the requirement of large dose of insulin in diabetic smokers compared to non-smokers to avail similar metabolic outcome.[1] In an experimental study (Glucose-clamp method), infusion of nicotine in both healthy and diabetic volunteers showed that in healthy volunteers there was no difference in concentration of serum insulin while in case of diabetic patients higher dose of insulin was required.[2,3] Nicotine has negative effect on insulin release and its action, suggesting nicotine to be one of the prominent causes of insulin resistance. Further nicotine induces loss of pancreatic $\beta$-cells via oxidative stress, mitochondrial dysfunction and inflammation. ${ }^{[4]}$

Chemicals present in cigarette smoke promote cellular injury thereby interfering its function and leading to inflammation. From the previous researches, it is evident that both oxidative stress and inflammation increase the diabetic risk. Diabetic patients who smoke are more prone to adverse health effects viz heart and renal diseases, diabetic foot infections or ulcers, retinopathy and peripheral neuropathy compared to non-smoker diabetic patients. Moreover, smoking has been shown to have significant contribution towards the mortality of diabetic patients due to CVD and CHD (Coronary Heart Disease). On an average, smokers are found to die 8-10 years earlier than those patients who do not smoke. It has been shown that the risk of CVD increases by $61 \%$ in those smokers who consume more than 20 cigarettes per day, $29 \%$ in smokers taking less than 20 cigarettes per day and $23 \%$ in the former smokers. ${ }^{[5]}$

Thus, the main objective of this study was to determine the association of smoking with inflammatory markers and the risk factors of cardiovascular diseases in pre-diabetic and diabetic patients so that our result may serve as mediator to promote cessation of smoking in diabetic patients in order to prevent blooming of diabetic vascular complications.

\section{METHODS}

This comparative cross-sectional study was commenced in Santosh Medical College and Hospital with 100 healthy controls, 145 pre-diabetic patients and 126 diabetic patients. The sample size was calculated by the formula:

Sample size $=(z \text { score at } 95 \%)^{2 *} \mathrm{p}^{*}(1-\mathrm{p}) / \mathrm{l}^{2}$

Where $p$ is the prevalence and $l$ is the error.

Prevalence of pre-diabetes and diabetes were $10.4 \%$ and $8.7 \%$ respectively in India. ${ }^{[6,7]}$ We enrolled the patients with no history of inflammatory diseases, cardiovascular diseases pregnancy etc that affected the concentration of inflammatory markers. Before commencement approval from the ethical board of institution was obtained.

Each participant keenly participated and gave the written consents in this research. Age, BMI (Body mass index), WHR (Waist hip ratio) of each participant were recorded. Biochemical parameters such as fasting glucose, glycosylated haemoglobin (HbA1c), cholesterol (CHO), HDL (High Density Lipoprotein), triglyceride (TG) and inflammatory parameters like adiponectin, fibrinogen, CRP, IL-6 and uric acid were estimated in blood sample of each patient.

\section{Sample Collection and Analysis}

Venous blood was collected aseptically by venipuncture of antecubital vein using tourniquet, vacutainer and sterile cotton swab (soaked in spirit). $1 \mathrm{ml}$ of fasting sample was collected in a fluoride vial (containing mixture of potassium oxalate and sodium fluoride in the ratio 3:1) for estimation of blood glucose. $1 \mathrm{ml}$ was collected in EDTA vial for estimation of HbA1c and fibrinogen. $3 \mathrm{ml}$ was collected in plain vial for estimation of lipid, uric acid, adiponectin and interleukin 6 . The samples in fluoride vial and plain vial were then centrifuged at $3000 \mathrm{rpm}$ for 15 minutes for separation of plasma and serum respectively. The samples in EDTA vial after HbA1c estimation was centrifuged at $3000 \mathrm{rpm}$ for 15 minutes for separation of plasma for the estimation of fibrinogen. The serum samples were stored at $-80^{\circ} \mathrm{C}$ until adiponectin and IL6 estimation.

Fasting glucose was measured by GOD-POD method, HbA1c was analysed using ion exchange resin method. Likewise, total cholesterol, HDL and TG were analysed by CHOD-POD, CHOD-POD/phosphotungstate method and GPOPAP method respectively. LDL (Low Density Lipoprotein) was computed from Friedwaldequation ${ }^{[8]}$ i.e. $\quad$ LDL=Total Cholesterol-[HDL+VLDL] where VLDL=TG/5. Inflammatory biomarkers like adiponectin and IL- 6 were assessed by ELISA while CRP and fibrinogen were estimated respectively by immunoturbidimetric method. Uric acid was detected by uricase method.

\section{The Cardiac Risk Indices ${ }^{[9]}$ were calculated as follows-}

Castelli's Risk Index I or Cardiac Risk Ratio (CRI I or CRR) $=\frac{\text { Total cholesterol }}{\text { HDL }}$

Castelli's Risk Index II or Atherogenic Index (CRI - II or AI)

$$
=\frac{\mathrm{LDL}}{\mathrm{HDL}}
$$

Atherogenic coefficient $(\mathrm{AC})=\frac{\text { Total cholesterol }- \text { HDL }}{\text { HDL }}$

Atherogenic index of plasma (AIP) $=\log \left(\frac{T G}{H D L}\right)$

\section{Statistical Analysis}

The concentration of study parameters (Age, WHR, BMI, fasting sugar, HbA1c, cholesterol, TG, HDL, LDL, adiponectin, fibrinogen, CRP, IL-6 and uric acid) were expressed as mean \pm SD. The differences in the level of these parameters among control, pre-diabetic group, and diabetic group were 
investigated by ANOVA and post hoc test. Student's t test was used to compare between non-smoker and smoker category of each patient group. The association between inflammatory mediators and other parameters included was determined by Pearson's correlation coefficient. The $\mathrm{p}<0.05$ was implicated to be statistically significant.

\section{RESULTS}

In table 1 the comparison of basic parameters among the three groups namely control, pre-diabetic and diabetic groups is shown. The analysis using ANOVA showed significant result that was followed by post hoc test (Table 1). The pre-diabetic and diabetic groups were further categorised based on their smoking habit. In table 2 comparisons of basic parameters between non-smoker and smoker is shown. There was no significant difference in the level of basic parameters when compared between pre-diabetic non-smoker/smoker groups and diabetic non-smoker/smoker groups. However, when the biochemical parameters were compared between pre-diabetic versus diabetic non-smoker groups and pre-diabetic versus diabetic smoker groups, significantly high values of fasting glucose, HbA1c and lipid parameters (LDL, TG) were obtained but the difference in HDL was significant only in case of prediabetic versus diabetic non-smoker group. Non-smoker diabetic subjects had low HDL level compared to non-smoker pre-diabetic subjects.

In this study we evaluated levels of inflammatory markers in both non-smoker and smoker categories of pre-diabetic and diabetic patients using ANOVA and post hoc test. Table 3 represents comparison between control, pre-diabetic and diabetic groups. Table 4 represents the comparative analysis among pre-diabetic and diabetic non-smoker and smoker group. Significantly high adiponectin and significantly low fibrinogen levels in pre-diabetic non-smoker patients compared to pre-diabetic smoker patients were observed. Similarly, significantly low adiponectin was observed in diabetic patients who smoked compared to the diabetic nonsmokers. When comparison was made between prediabetic/diabetic non-smokers and pre-diabetic/diabetic smokers, significantly high values of fibrinogen, CRP, IL- 6 and uric acid, and significantly low level of adiponectin were observed in case of patients of diabetic category (Non-smoker and smoker). In tables 5 and 6, cardiac risk indices were assessed among the three study groups (Control, pre-diabetic and diabetic) as well as the non-smoker and smoker category of pre-diabetic and diabetic patients. The risk of CVD was significantly high in both pre-diabetic and diabetic subjects as indicated by higher values of cardiac risk indices compared to control group (Table 5). However, when comparison was made among pre-diabetic non-smoker/smoker patients and diabetic non-smoker and smoker patients, the level of cardiac risk indices were high in pre-diabetic and diabetic patients who smoked. In case of pre-diabetic versus diabetic nonsmoker and smoker categories diabetic patients showed significant increase in the level of all the indices (Table 6). The inflammatory markers were correlated with the cardiac risk indices and the correlation was statistically significant irrespective of smoking habit of pre-diabetic and diabetic individuals (Table 7 and 8).

\begin{tabular}{|c|c|c|c|c|}
\hline Parameter & Control C & Pre-Diabetes (P) & Diabetes (D) & p (ANOVA) \\
\hline Age (years) & $42.87 \pm 7.87^{\mathrm{a}^{*}}$ & \begin{tabular}{|l}
$48.04 \pm 6.78^{\mathrm{c}}$ \\
\end{tabular} & $49.67 \pm 10.26^{b^{*}}$ & $<0.0001^{*}$ \\
\hline BMI & $23.42 \pm 2.1^{\mathrm{a}}$ & $23.99 \pm 2.4^{c}$ & $24.35 \pm 2.72^{b^{*}}$ & $0.0142^{*}$ \\
\hline WHR & $0.85 \pm 0.08^{a^{*}}$ & $0.91 \pm 0.12^{\mathrm{c}}$ & $0.9 \pm 0.12^{\mathrm{b}^{*}}$ & $0.0006^{*}$ \\
\hline $\begin{array}{l}\text { Fasting } \\
\text { Glucose } \\
\text { (mg/dL) }\end{array}$ & $84.53 \pm 7.24^{a^{*}}$ & $116.63 \pm 5.15^{c^{*}}$ & $160.49 \pm 40.15^{b^{*}}$ & $<0.0001^{*}$ \\
\hline HbA1c (gm\%) & $5.05 \pm 0.53^{a^{*}}$ & $5.87 \pm 0.44 \mathrm{c}^{*}$ & $6.36 \pm 0.89^{\mathrm{b}^{*}}$ & $<0.0001^{*}$ \\
\hline CHO $(\mathrm{mg} / \mathrm{dL})$ & $173.27 \pm 13.58^{\mathrm{a}^{*}}$ & $186.64 \pm 25.98^{c}$ & $195.59 \pm 35.68^{\mathrm{b}^{*}}$ & $<0.0001^{*}$ \\
\hline $\mathrm{HDL}(\mathrm{mg} / \mathrm{dL})$ & $49 \pm 5.18^{\mathrm{a}}$ & $48.19 \pm 4.49^{c^{*}}$ & $46.12 \pm 4.73^{\mathrm{b}^{*}}$ & $<0.0001^{*}$ \\
\hline $\mathrm{TG}(\mathrm{mg} / \mathrm{dL})$ & $105 \pm 21.27 \mathrm{a}$ & $110.37 \pm 20.96 \mathrm{c}^{*}$ & $123.1 \pm 37.44^{b^{*}}$ & $<0.0001^{*}$ \\
\hline LDL $(\mathrm{mg} / \mathrm{dL})$ & $103.1 \pm 13.2^{a^{*}}$ & $116.28 \pm 28.21^{\mathrm{c}}$ & $124.8 \pm 35.14 \mathrm{~b}^{*}$ & $<0.0001^{*}$ \\
\hline \multicolumn{5}{|c|}{$\begin{array}{c}\text { Table 1. Comparison of Basic Parameters in Control, } \\
\text { Pre-Diabetes and Diabetes }\end{array}$} \\
\hline \multicolumn{5}{|c|}{$\begin{array}{l}* \rightarrow \text { Statistically Significant. } \\
a, b \text { and c indicate the post hoc analysis among the study groups. } \\
a \rightarrow \text { Control Vs Prediabetes } \\
b \rightarrow \text { Control Vs Diabetes } \\
c \rightarrow \text { Pre-diabetes Vs Diabetes }\end{array}$} \\
\hline
\end{tabular}

\begin{tabular}{|c|c|c|c|c|}
\hline Parameter & \begin{tabular}{|c|}
$\begin{array}{c}\text { Pre-Diabetes } \\
\text { (Non- } \\
\text { smoker) }\end{array}$ \\
\end{tabular} & $\begin{array}{l}\text { Pre-Diabetes } \\
\text { (Smoker) }\end{array}$ & $\begin{array}{c}\text { Diabetes } \\
\text { (Non- } \\
\text { Smoker) }\end{array}$ & $\begin{array}{l}\text { Diabetes } \\
\text { (Smoker) }\end{array}$ \\
\hline Age (years) & & & $49.36 \pm 9.93^{b}$ & 50.35 \\
\hline & & & & \\
\hline WHR & & & & \\
\hline $\begin{array}{c}\text { Fasting Glucose } \\
(\mathrm{mg} / \mathrm{dL})\end{array}$ & $117.28 \pm 4.92^{\mathrm{a}^{*}}$ & $115.14 \pm 5.43^{c^{* *}}$ & $160.11 \pm 43.53^{\mathrm{b} *}$ & $161.31 \pm 32.19^{d}$ \\
\hline HbA1c (gm\%) & $5.85 \pm 0.47 \mathrm{a}$ & $5.9 \pm 0.37 \mathrm{c}^{* *}$ & $0.88^{\mathrm{b}^{* *}}$ & $6.41 \pm 0.92^{\mathrm{d}}$ \\
\hline CHO (mg/dL) & $186.86 \pm 26.96^{\mathrm{a}}$ & $186.1 \pm 23.87 \mathrm{c}$ & $6.61^{\mathrm{b}}$ & $34.02^{\mathrm{d}}$ \\
\hline HDL (mg/dL) & $48.3 \pm 4.26^{\mathrm{a}}$ & $48 \pm 5.02^{\mathrm{c}}$ & $45.87 \pm 4.61^{\mathrm{b}^{* *}}$ & $46.65 \pm 5^{\mathrm{d}}$ \\
\hline $\mathrm{TG}(\mathrm{mg} / \mathrm{dL})$ & $112.9 \pm 21.99^{\mathrm{a}}$ & $105.93 \pm 17.8^{\mathrm{c}^{* *}}$ & $123.67 \pm 40.94^{\mathrm{b}^{*}}$ & $121.88 \pm 28.92^{\mathrm{d}}$ \\
\hline $\mathrm{LDL}(\mathrm{mg} / \mathrm{dL})$ & $116 \pm 28.99^{a}$ & $116.9 \pm 26.65^{c}$ & $125.61 \pm 35.15^{\mathrm{b}^{*}}$ & $123.19 \pm 35.51^{\mathrm{d}}$ \\
\hline \multicolumn{5}{|c|}{$\begin{array}{c}\text { Table 2. Comparison of Basic Parameters in Pre-Diabetic and Diabetic } \\
\text { Non-Smoker and Smoker Groups }\end{array}$} \\
\hline \multicolumn{5}{|c|}{$\begin{array}{l}\text { Statistically significant }\left(\mathrm{t} \text {-test): }{ }^{*} \rightarrow \mathrm{p}<0.05^{* *} \rightarrow \mathrm{p}<0.01\right. \\
\mathrm{a} \rightarrow \text { Pre-diabetic non-smoker Vs smoker } \\
\mathrm{b} \rightarrow \text { Pre-diabetic non-smoker Vs Diabetic non smoker } \\
\mathrm{c} \rightarrow \text { Pre-diabetic smoker Vs Diabetic smoker } \\
\mathrm{d} \rightarrow \text { Diabetic non-smoker Vs Diabetic smoker }\end{array}$} \\
\hline
\end{tabular}

\begin{tabular}{|c|c|c|c|c|}
\hline Parameters & $\begin{array}{c}\text { Control } \\
\mathrm{C}\end{array}$ & $\begin{array}{c}\text { Pre-Diabetes } \\
\text { (P) }\end{array}$ & $\begin{array}{c}\text { Diabetes } \\
\text { (D) }\end{array}$ & $\begin{array}{c}p \\
\text { (ANOVA) }\end{array}$ \\
\hline Adiponectin (ug $/ \mathrm{mL}$ ) & $9.01 \pm 2.82^{\mathrm{a}^{*}}$ & $8.15 \pm 1.87 \mathrm{c}^{*}$ & $6.84 \pm 1.98 \mathrm{~b}^{*}$ & $<0.0001^{*}$ \\
\hline $\mathrm{CRP}(\mathrm{mg} / \mathrm{L})$ & $2.81 \pm 1.13^{a^{*}}$ & $4.17 \pm 1.36 c^{*}$ & $5.15 \pm 1.73 \mathrm{~b}^{*}$ & $<0.0001^{*}$ \\
\hline IL-6 (pg/mL) & $4.31 \pm 1.8^{\mathrm{a}^{*}}$ & $5.87 \pm 1.6 c^{*}$ & $7.51 \pm 2.25 \mathrm{~b}^{*}$ & $<0.0001^{*}$ \\
\hline Fibrinogen $(\mathrm{mg} / \mathrm{dL})$ & $331.18 \pm 58.61^{\mathrm{a}}$ & $346.58 \pm 55.78 c^{*}$ & $369.6 \pm 61.38 \mathrm{~b}$ & $<0.0001^{*}$ \\
\hline Uric acid (mg/dL) & $4.47 \pm 0.76^{\mathrm{a}}$ & $4.64 \pm 1.04 \mathrm{c}^{*}$ & $6.33 \pm 1.89 \mathrm{~b}^{*}$ & $<0.0001^{*}$ \\
\hline \multicolumn{5}{|c|}{$\begin{array}{l}\text { Table 3. Comparison of Markers of Inflammation in Control, } \\
\text { Pre-Diabetes and Diabetes }\end{array}$} \\
\hline \multicolumn{5}{|c|}{$\begin{array}{l}* \rightarrow \text { Statistically Significant } \\
\text { a, b and c indicate the post hoc analysis among the study groups. } \\
a \rightarrow \text { Control Vs Pre-diabetes } \\
b \rightarrow \text { Control Vs Diabetes } \\
c \rightarrow \text { Pre-diabetes Vs Diabetes }\end{array}$} \\
\hline
\end{tabular}

\begin{tabular}{|c|c|c|c|c|}
\hline Parameter & $\begin{array}{c}\text { Pre-Diabetes } \\
\text { (Non-smoker) }\end{array}$ & $\begin{array}{c}\text { Pre-Diabetes } \\
\text { (Smoker) }\end{array}$ & $\begin{array}{c}\text { Diabetes } \\
\text { (Non-Smoker) }\end{array}$ & $\begin{array}{c}\text { Diabetes } \\
\text { (Smoker) }\end{array}$ \\
\hline $\begin{array}{c}\text { Adiponectin } \\
\text { (ug/mL) }\end{array}$ & $8.36 \pm 1.95^{\mathrm{a}^{*}}$ & $7.67 \pm 1.58^{\mathrm{c}^{* *}}$ & $7.03 \pm 2.27^{\mathrm{b}^{* *}}$ & $6.43 \pm 1.02^{\mathrm{d}^{*}}$ \\
\hline CRP (mg/L) & $4.16 \pm 1.43^{\mathrm{a}}$ & $4.18 \pm 1.21^{\mathrm{c}^{* *}}$ & $5.1 \pm 1.77^{\mathrm{b}^{* *}}$ & $5.26 \pm 1.67^{\mathrm{d}}$ \\
\hline IL-6 (pg/mL) & $5.84 \pm 1.61^{\mathrm{a}}$ & $5.94 \pm 1.57 \mathrm{c}^{* *}$ & $7.4 \pm 2.33^{\mathrm{b}^{* *}}$ & $7.75 \pm 2.07^{\mathrm{d}}$ \\
\hline $\begin{array}{c}\text { Fibrinogen } \\
\text { (mg/dL) }\end{array}$ & $340.45 \pm 55.79^{\mathrm{a}^{*}}$ & $360.68 \pm 43.89 \mathrm{c}$ & $367.36 \pm 59.43^{\mathrm{b}^{* *}}$ & $374.42 \pm 65.9^{\mathrm{d}}$ \\
\hline $\begin{array}{c}\text { Uric acid } \\
\text { (mg/dL) }\end{array}$ & $4.69 \pm 1.04^{\mathrm{a}}$ & $4.53 \pm 1.04^{\mathrm{c}^{* *}}$ & $6.27 \pm 1.88^{\mathrm{b}^{* *}}$ & $6.46 \pm 1.93^{\mathrm{d}}$ \\
\hline
\end{tabular}

Table 4. Comparison of Markers of Inflammation in

Pre-Diabetic and Diabetic Non-Smoker and Smoker Groups

Statistically significant (test): ${ }^{*} \rightarrow \mathrm{p}<0.05^{* *} \rightarrow \mathrm{p}<0.01$

$a \rightarrow$ Pre-diabetic non-smoker Vs smoker

$\mathrm{b} \rightarrow$ Pre-diabetic non-smoker Vs Diabetic non smoker

$c \rightarrow$ Pre-diabetic smoker Vs Diabetic smoker

$\mathrm{d} \rightarrow$ Diabetic non-smoker Vs Diabetic smoker

\begin{tabular}{|l|c|c|c|c|}
\hline Parameter & Control C & Pre-Diabetes (P) & Diabetes (D) & (ANOVA) \\
\hline
\end{tabular}

\begin{tabular}{|c|c|c|c|c|}
\hline Parameter & Control C & Pre-Diabetes (P) & Diabetes (D) & p (ANOVA) \\
\hline CRR & $3.6 \pm 0.5^{a^{*}}$ & $3.92 \pm 0.82^{c^{*}}$ & $4.32 \pm 1.09^{\mathrm{b}^{*}}$ & $<0.0001^{*}$ \\
\hline $\mathrm{AI}$ & $2.1 \pm 0.4^{a^{*}}$ & $2.46 \pm 0.78^{c^{*}}$ & $2.77 \pm 0.97^{\mathrm{b}^{*}}$ & $<0.0001^{*}$ \\
\hline $\mathrm{AC}$ & $2.58 \pm 0.53^{a^{*}}$ & $2.93 \pm 0.82^{c^{*}}$ & $3.32 \pm 1.09^{\mathrm{b}^{*}}$ & $<0.0001^{*}$ \\
\hline AIP & $0.32 \pm 0.1^{\mathrm{a}}$ & $0.35 \pm 0.09^{c^{*}}$ & $0.41 \pm 0.15^{\mathrm{b}^{*}}$ & $<0.0001^{*}$ \\
\hline \multicolumn{5}{|c|}{$\begin{array}{c}\text { Table 5. Comparison of Cardiac Risk Indices in Control, } \\
\text { Pre-Diabetes and Diabetes }\end{array}$} \\
\hline \multicolumn{5}{|c|}{$\begin{array}{l}* \rightarrow \text { Statistically Significant } \\
a, b \text { and c indicate the post hoc analysis among the study groups. } \\
a \rightarrow \text { Control Vs Pre-diabetes } \\
b \rightarrow \text { Control Vs Diabetes } \\
c \rightarrow \text { Pre-diabetes Vs Diabetes }\end{array}$} \\
\hline
\end{tabular}




\begin{tabular}{|c|c|c|c|c|}
\hline Parameter & $\begin{array}{c}\text { Pre-Diabetes } \\
\text { (Non-Smoker) }\end{array}$ & $\begin{array}{c}\text { Pre-Diabetes } \\
\text { (Smoker) }\end{array}$ & $\begin{array}{c}\text { Diabetes } \\
\text { (Non-Smoker) }\end{array}$ & $\begin{array}{c}\text { Diabetes } \\
\text { (Smoker) }\end{array}$ \\
\hline $\mathrm{CRR}$ & $3.91 \pm 0.82^{\mathrm{a}}$ & $3.94 \pm 0.83^{\mathrm{c}^{* *}}$ & $4.23 \pm 0.94^{\mathrm{b}^{* *}}$ & $4.365 \pm 1.16^{\mathrm{d}}$ \\
\hline $\mathrm{AI}$ & $2.451 \pm 0.78^{\mathrm{a}}$ & $2.49 \pm 0.78^{\mathrm{c}^{*}}$ & $2.696 \pm 0.88^{\mathrm{b}^{* *}}$ & $2.814 \pm 1.02^{\mathrm{d}}$ \\
\hline $\mathrm{AC}$ & $2.93 \pm 0.82^{\mathrm{a}}$ & $2.94 \pm 0.83^{\mathrm{c}^{* *}}$ & $3.23 \pm 0.94^{\mathrm{b}^{* *}}$ & $3.37 \pm 1.16^{\mathrm{d}}$ \\
\hline AIP & $0.36 \pm 0.1^{\mathrm{a}}$ & $0.339 \pm 0.09^{\mathrm{c}^{*}}$ & $0.41 \pm 0.13^{\mathrm{b}^{* *}}$ & $0.41 \pm 0.15^{\mathrm{d}}$ \\
\hline \multicolumn{5}{|c|}{ Table 6. Comparison of Cardiac Risk Indices in Pre-Diabetic } \\
and Diabetic Non-Smoker and Smoker Groups \\
$\begin{array}{l}\text { Statistically significant }\left(\mathrm{t} \text { test): }{ }^{*} \rightarrow \mathrm{p}<0.05^{* *} \rightarrow \mathrm{p}<0.01\right. \\
\mathrm{a} \rightarrow \text { Pre-diabetic non-smoker vs smoker } \\
\mathrm{b} \rightarrow \text { Pre-diabetic non-smoker vs diabetic non smoker } \\
\mathrm{c} \rightarrow \text { Pre-diabetic smoker vs diabetic smoker } \\
\mathrm{d} \rightarrow \text { Diabetic non-smoker vs diabetic smoker }\end{array}$
\end{tabular}

\begin{tabular}{|c|c|c|c|c|c|c|c|c|}
\hline \multirow{2}{*}{ Parameter } & Pre-Diabetic Non-Smoker (r) & \multicolumn{3}{|c|}{ Pre-diabetic Smoker (r) } \\
\cline { 2 - 9 } & CRR & AI & AC & AIP & CRR & AI & AC & AIP \\
\hline Adiponectin & $-0.25^{*}$ & $-0.23^{*}$ & $-0.27^{* *}$ & $-0.34^{* *}$ & $-0.44^{* *}$ & $-0.44^{* *}$ & $-0.44^{* *}$ & -0.25 \\
\hline CRP & $0.21^{*}$ & $0.21^{*}$ & $0.22^{*}$ & $0.21^{*}$ & 0.27 & 0.25 & 0.27 & 0.2 \\
\hline IL-6 & 0.15 & 0.12 & 0.16 & $0.35^{* *}$ & 0.01 & 0.03 & 0.01 & 0.23 \\
\hline Fibrinogen & 0.17 & 0.18 & $0.21^{*}$ & 0.15 & $0.5^{* *}$ & $0.48^{* *}$ & $0.5^{* *}$ & $0.44^{* *}$ \\
\hline Uric acid & 0.18 & 0.15 & 0.16 & 0.11 & 0.07 & 0.07 & 0.07 & 0.06 \\
\hline Table 7. Correlation of Inflammatory Markers with Cardiac Risk \\
Factors in Pre-Diabetic Non-Smoker and Smoker Groups \\
\hline
\end{tabular}

\begin{tabular}{|c|c|c|c|c|c|c|c|c|}
\hline \multirow{2}{*}{ Parameter } & \multicolumn{3}{|c|}{ Diabetic Non-Smoker (r) } & \multicolumn{4}{c|}{ Diabetic Smoker (r) } \\
\cline { 2 - 9 } & CRR & AI & AC & AIP & CRR & AI & AC & AIP \\
\hline Adiponectin & $-0.3^{* *}$ & -0.22 & $-0.3^{* *}$ & $-0.51^{* *}$ & $-0.5^{* *}$ & $-0.47^{* *}$ & $-0.5^{* *}$ & $-0.54^{* *}$ \\
\hline CRP & $0.73^{* *}$ & $0.69^{* *}$ & $0.73^{* *}$ & $0.62^{* *}$ & $0.66^{* *}$ & $0.62^{* *}$ & $0.66^{* *}$ & $0.55^{* *}$ \\
\hline IL-6 & $0.44^{* *}$ & $0.42^{* *}$ & $0.44^{* *}$ & $0.43^{* *}$ & $0.54^{* *}$ & $0.48^{* *}$ & $0.54^{* *}$ & $0.61^{* *}$ \\
\hline Fibrinogen & $0.31^{* *}$ & $0.32^{* *}$ & $0.31^{* *}$ & 0.15 & $0.4^{*}$ & $0.36^{*}$ & $0.4^{*}$ & $0.37^{*}$ \\
\hline Uric acid & $0.26^{*}$ & $0.23^{*}$ & 0.01 & $0.31^{* *}$ & 0.39 & $0.42^{* *}$ & $0.39^{*}$ & $0.26^{*}$ \\
\hline \multicolumn{1}{|c|}{ Table 8. Correlation of Inflammatory Markers with } \\
Cardiac Risk Factors in Diabetic Non-Smoker and Smoker Groups \\
Statistically significant: ${ }^{*} \rightarrow \mathrm{p}<0.05^{* *} \rightarrow \mathrm{p}<0.01$ \\
\hline
\end{tabular}

\section{DISCUSSION}

Smoking increases diabetes incidence in a dose dependent manner. Several cohort studies have demonstrated increased risk of diabetes induced by smoking. A four year follow up study of Cho et al reported significantly elevated diabetic risk in both past and current smokers. The authors also suggested an increase in the risk with the increase in number of cigarette intake.[10] Similarly, in another 14 years long cohort study, it was shown that risk of diabetes was 1.55 among the individuals who smoked $\geq 20$ cigarettes/day compared to the non-smokers. ${ }^{[11]}$ Further, in another follow up study ${ }^{[12]}$ and a British study, ${ }^{[13]}$ the risk of diabetes was reported to 1.94 and 1.7 respectively. The exact mechanism on how smoking increases diabetic risk though unclear, it is depicted that smoking induces increase in hyperglycaemic hormones like epinephrine and nor epinephrine that may contribute to blood glucose by promoting hepatic glycogenolysis and gluconeogenesis. ${ }^{[14]}$ Further smoking causes generation of free radicals that promote lipid peroxidation, DNA damage and protein oxidation thereby leading to pancreatic $\beta$-cell apoptosis.[15] Oxidative stress induced due to smoking is also responsible for the systemic inflammation and endothelial dysfunction observed in diabetic patients. Also smoking has been implicated to contribute to dyslipidemia which is the major attributor to atherosclerosis. Smokers are shown to have high TG, FFA (free fatty acids), LDL and low HDL levels thereby suggesting pathological relationship between diabetic vascular disease and smoking. [16]

In this study we evaluated levels of inflammatory markers like adiponectin, fibrinogen, CRP, IL-6 and uric acid in prediabetic and diabetic patients and compared that with the control groups. We also assessed cardiovascular risk in the form of cardiac risk indices and correlated them with inflammatory parameters in both pre-diabetic and diabetic non-smoker and smoker groups. We did not find significant differences in the level of basic parameters when compared between pre-diabetic non-smoker versus smoker groups and diabetic non-smoker versus smoker groups. However, on comparative analysis between pre-diabetic versus diabetic groups in both non-smoker and smoker categories significant differences were observed in case of fasting glucose, HbA1c, HDL, TG and LDL. On analysing the levels of inflammatory markers among non-smoker and smoker pre-diabetic and diabetic patients we observed significantly low adiponectin level in both pre-diabetic and diabetic smoker groups compared to their non-smoker counterparts. We could also document significantly high fibrinogen in pre-diabetic smokers compared to pre-diabetic non-smokers. The level of IL-6, CRP and uric acid though were high in smoker group, the level of statistical significance could not be achieved in both the patients (pre-diabetic and diabetic).

Thamer $\mathrm{C}$ et al[17] and Kotani $\mathrm{K}$ et al[18] in their study showed decrease in adiponectin level due to smoking. Likewise, Levitzky YS et al[19] and Hastie CE et al[20] demonstrated positive association between CRP and smoking. According to Efstathiou SP et al smoking induces decrease in adiponectin is temporary since cessation of smoking facilitates increase in the level of serum adiponectin to the normal level.[21] One of the plausible mechanisms for smoking induced decrease in adiponectin level could be the oxidative stress that leads to the deactivation of PI-3 kinase (Phosphatidyl inositol 3 kinase) which is a key protein for expression and secretion of adiponectin from adipocytes.[22] Further chronic smoking also causes increased production of TNF- $\alpha$ that promotes hypoadiponectinemia.[23] Nicotine present in smoke further reduces the expression of adiponectin mRNA in adipocytes.[22]

Smoking is a chief contributor of CVD independent of diabetic status of the subject. The risk is further amplified if the subject is hyperglycaemic. A prospective 8 years follow up study showed significant association of CHD (Coronary heart disease) with smoking in diabetic patients. Similar results were obtained in the UKPD study too. ${ }^{[24,25]}$ The Nurses Health study demonstrated the dose dependent increase in CHD risk among diabetic women who smoked. The relative risks were depicted to be 1.66 and 2.68 for those who consumed 1-14 cigarettes/day and $\geq 15$ cigarettes/day respectively.[26] Similarly, a meta-analysis study demonstrated hazard ratio of 1.42 for CHD in diabetic patients who were current smokers compared to the non-smokers. The authors also suggested that cessation of smoking can culminate greater benefits to diabetic patients by lowering the burden of CVD.[27] Keeping this in view we assessed the future risk of CVD in patients with prediabetes and diabetes by evaluating various cardiac risk indices such as CRR, AI, AC and AIP with respect to smoking status. Independent of smoking status we found significantly high cardiac risk inHdices in patients with pre-diabetes and diabetes compared to controls. On categorising the patients based on smoking status, increased levels of cardiac risk indices were observed in pre-diabetic smokers and diabetic smokers compared to their non-smoker counterparts, however the increase was not significant statistically. Significantly high values were documented in diabetic nonsmoker and smoker groups when comparison was made with 
the respective non-smoker counterparts. Since smoking also induces systemic inflammation that contributes to diabetes and CVD, in this study we determined the association between inflammatory mediators and cardiac risk indices. In case of pre-diabetic smoker group, adiponectin and fibrinogen showed significant negative and positive association respectively while in case of pre-diabetic non-smoker group such association was observed in case of adiponectin and CRP respectively. In case of diabetic patients, all the assayed inflammatory parameters were significantly correlated with cardiac risk indices and the correlation was more pronounced in diabetic patients who smoked. The correlation with adiponectin was negative while with fibrinogen, CRP, IL- 6 and uric acid was positive.

\section{CONCLUSIONS}

Smoking has harmful effects in diabetic patients like increasing CV mortality. Smoking promotes insulin resistance, inversely affects insulin function, causes oxidative damage and induces inflammatory phenomena, all of which are key to diabetic complications, especially macro vascular ones. The results of our study also supported this fact as we observed elevated cardiovascular risks and significant association of inflammatory mediators with these risk factors (cardiac risk indices) in pre-diabetic and diabetic subjects. Thus, it is recommended that these patients should be educated on the adverse outcomes of smoking and encouraged to quit smoking, since cessation of smoking can also restore the level of cardioprotective cytokine adiponectin. Also, further studies are to be sought regarding effects of cigarette smoking on glucose metabolism and inflammatory responses leading to development of CVD as there is paucity of research in this regard.

\section{REFERENCES}

[1] Naudi A, Jove M, Ayala V, et al. Cellular dysfunction in diabetes as maladaptive response to mitochondrial oxidative stress. Article ID 696215, Exp Diabetes Res 2012;2012:1-14.

[2] Holloway AC, Lim GE, Petrik JJ, et al. Fetal and neonatal exposure to nicotine in Wistar Rats results in increased beta cell apoptosis at birth and postnatal endocrine and metabolic changes associated with type 2 diabetes. Diabetologia 2005;48(12):2661-6.

[3] Axelsson T, Jansson PA, Smith U, et al. Nicotine infusion acutely impairs insulin sensitivity in type 2 diabetic patients but not in healthy subjects. J Intern Med 2001;249(6):539-44.

[4] Xie XT, Liu Q, Wu J, et al. Impact of cigarette smoking in type 2 diabetes development. Acta Pharmacol Sin 2009;30(6):784-7.

[5] Willi C, Bodenmann P, Ghali WA, et al. Active smoking and the risk of type 2 diabetes: a systematic review and metaanalysis. JAMA 2007;298(22):2654-64.
[6] Singh PS, Sharma H, Zafar KS, et al. Prevalence of type 2 diabetes mellitus in rural population of India. A study from western Uttar Pradesh. International Journal of Research in Medical Sciences 2017;5(4):1363-7.

[7] Kumar M, Arya R, Shukla MK, et al. Community based cross sectional study on prevalence of risk factors of type 2 diabetes mellitus in adult population residing in urban area of Shahjahanpur, Uttar Pradesh. IAIM 2017;4(10):216-20.

[8] Nimmanapalli HD, Kasi AD, Devapatla PK, et al. Lipid ratios, atherogenic coefficient and atherogenic index of plasma as parameters in assessing cardiovascular risk in type 2 diabetes mellitus. Int $\mathrm{J}$ Res Med Sci 2016;4(7):2863-9.

[9] Bhardwaj S, Bhattacharjee J, Bhatnagar MK, et al. Atherogenic index of plasma, Castelli risk index and atherogenic coefficient - new parameters in assessing cardiovascular risk. Int J Pharm Bio Sci 2013;3(3):359-64.

[10] Cho NH, Chan JC, Jang HC, et al. Cigarette smoking is an independent risk factor for type 2 diabetes: a four-year community-based prospective study. Clin Endocrinol (Oxf) 2009;71(5):679-85.

[11] Jee SH, Foong AW, Hur NW, et al. Smoking and risk for diabetes incidence and mortality in Korean men and women. Diabetes Care 2010;33(12):2567-72.

[12] Rimm EB, Chan J, Stampfer MJ, et al. Prospective study of cigarette smoking, alcohol use and the risk of diabetes in men. BMJ 1995;310(6979):555-9.

[13] Wannamethee SG, Shaper AG, Perry IJ. Smoking as a modifiable risk factor for type 2 diabetes in middle-aged men. British Regional Heart Study. Diabetes Care 2001;24(9):1590-5.

[14] Hilawe EH, Yatsuya H, Li Y, et al. Smoking and diabetes: is the association mediated by adiponectin, leptin or Creactive protein? J Epidemiol 2015;25(2):99-109.

[15] Bhattacharjee A, Prasad SK, Pal S, et al. Synergistic protective effect of folic acid and vitamin B 12 against nicotine-induced oxidative stress and apoptosis in pancreatic islets of the rat. Pharm Biol 2016;54(3):43344.

[16] Berlin I. Smoking-induced metabolic disorders: a review. Diabetes Metab 2008;34(4 Pt 1):307-14.

[17] Thamer C, Stefan N, Stumvoll M, et al. Reduced adiponectin serum levels in smokers. Atherosclerosis 2005;179(2):421-2.

[18] Kotani K, Hazama A, Hagimoto A, et al. Adiponectin and smoking status: a systematic review. J Atheroscler Thromb 2012;19(9):787-94.

[19] Levitzky YS, Guo CY, Rong J, et al. Relation of smoking status to a panel of inflammatory markers: the Framingham offspring. Atherosclerosis 2008;201(1):217-24.

[20] Hastie CE, Haw S, Pell JP. Impact of smoking cessation and lifetime exposure on C-reactive protein. Nicotine Tob Res 2008;10(4):637-42.

[21] Efstathiou SP, Skeva II, Dimas C, et al. Smoking cessation increases serum adiponectin levels in an apparently healthy Greek population. Atherosclerosis 2009;205(2):632-6.

[22] Iwashima Y, Katsuya T, Ishikawa K, et al. Association of hypoadiponectinemia with smoking habit in men. Hypertension 2005;45(6):1094-100. 
[23] Yamauchi T, Kamon J, Minokoshi Y, et al. Adiponectin stimulates glucose utilization and fatty-acid oxidation by activating AMP-activated protein kinase. Nat Med 2002;8(11):1288-95.

[24] Morrish NJ, Stevens LK, Fuller JH, et al. Risk factors for macrovascular disease in diabetes mellitus: the London follow-up to the WHO Multinational Study of Vascular Disease in Diabetics. Diabetologia 1991;34(8):590-4.

[25] Turner RC, Millns H, Neil HA, et al. Risk factors for coronary artery disease in non-insulin dependent diabetes mellitus: United Kingdom Prospective Diabetes Study (UKPDS: 23). BMJ 1998;316(7134):823-8.
[26] Al-Delaimy WK, Manson JE, Solomon CG, et al. Smoking and risk of coronary heart disease among women with type 2 diabetes mellitus. Arch Intern Med 2002;162(3):273-9.

[27] Kengne AP, Nakamura K, Barzi F, et al. Smoking, diabetes and cardiovascular diseases in men in the Asia Pacific region. J Diabetes 2009;1(3):173-81. 